\section{Commentary: We must constantly look at things in different ways}

\author{
Luca Bertolaccini, MD, PhD, FCCP, \\ Elena Prisciandaro, MD, ${ }^{\mathrm{a}}$ and \\ Lorenzo Spaggiari, $\mathrm{MD}, \mathrm{PhD}^{\mathrm{a}, \mathrm{b}}$
}

Due to the advancement of imaging technologies, there has been an increase in the frequency of detection of unforeseen small, nonpalpable lung nodules. Several studies have demonstrated the feasibility of fluorescence to reveal nonpalpable nodules during surgery. ${ }^{1-3}$ Tokuno and colleagues ${ }^{4}$ evaluated the efficacy of a novel indocyanine green virtual-assisted lung mapping technology (VAL-MAP) to determine the nodule location for all thoracic surgery procedures (atypical or typical segmentectomies and lobectomies). Nevertheless, the long-awaited randomized controlled trial JCOG0802 (reported at the last 101st American Association for Thoracic Surgery Annual Meeting in the 2021 spring) proved that segmentectomy has improved survival, compared with lobectomy, for lung tumors $\leq 2 \mathrm{~cm}$. It is thus reasonable to assume that segmentectomies will become an alternative to lobectomies for stage IA disease. Nonetheless, 2 pillars must be established before segmentectomies may be considered the standard of care for this subset of patients, with subsequent widespread adoption by thoracic surgeons: the noninferiority of segmentectomy to lobectomy in terms of oncologic efficacy and the technical feasibility. ${ }^{5}$

Therefore, marking procedures will become essential for minimally invasive resections of nonpalpable nodules. VAL-MAP could be employed for suspected or

From the ${ }^{\text {aDDepartment }}$ of Thoracic Surgery, IEO, European Institute of Oncology IRCCS; and ${ }^{\mathrm{b}}$ Department of Oncology and Hemato-Oncology, University of Milan, Milan, Italy.

This work was partially supported by the Italian Ministry of Health with Ricerca Corrente and $5 \times 1000$ funds.

Disclosures: The authors reported no conflicts of interest.

The Journal policy requires editors and reviewers to disclose conflicts of interest and to decline handling or reviewing manuscripts for which they may have a conflict of interest. The editors and reviewers of this article have no conflicts of interest.

Received for publication Aug 10, 2021; revisions received Aug 10, 2021; accepted for publication Aug 11, 2021; available ahead of print Aug 16, 2021.

Address for reprints: Luca Bertolaccini, MD, PhD, FCCP, Division of Thoracic Surgery, IEO, European Institute of Oncology IRCCS, Via Ripamonti 435, $20141 \mathrm{Mi}$ lan, Italy (E-mail: luca.bertolaccini@gmail.com).

JTCVS Techniques 2021;10:550-1

2666-2507

Copyright (c) 2021 The Author(s). Published by Elsevier Inc. on behalf of The American Association for Thoracic Surgery. This is an open access article under the CC BY-NC-ND license (http://creativecommons.org/licenses/by-nc-nd/4.0/).

https://doi.org/10.1016/j.xjtc.2021.08.016

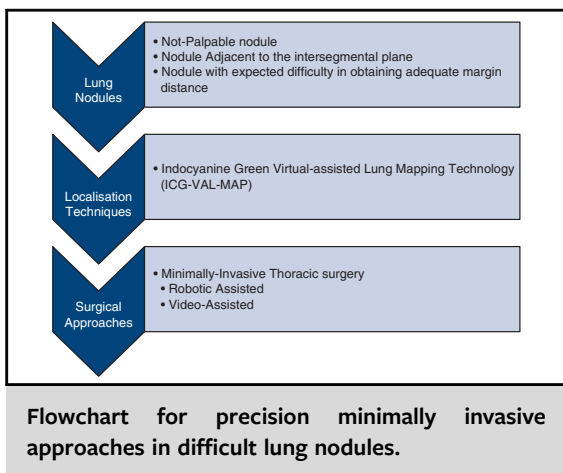

CENTRAL MESSAGE

Hybrid approach with virtualassisted lung mapping (VALMAP) and indocyanine green (ICG) injection showed efficacy, allowing us to perform segmentectomies, even with a minimally invasive approach.

pathologically confirmed malignant lung nodules whose intraoperative identification is challenging. These include (but are not limited to) pure ground-glass nodules and nodules smaller than $5 \mathrm{~mm} .{ }^{6}$ VAL-MAP alone gives indirect information about the tumor's location while establishing the direction of the staple line, with an acceptable risk of inaccuracy, as there are no objective indices for the evaluation of the tumor's depth, direction, and vector. While operating in an unpredictable environment, the surgeons must identify the direction and distance of the staple line empirically. ${ }^{7}$ Moreover, the margin depth was the most significant factor contributing to resection failure in segmentectomies performed with VAL-MAP. ${ }^{8}$

Therefore, the tumor location is crucial for the thoracic surgeons performing segmentectomies. When nodules are found in peripheral segments or intersegmental planes, it is critical to carefully consider the tumor location and segmental region to provide radical surgical margins. ${ }^{9}$

In conclusion, accurate knowledge of the nodule and intersegmental plane is required to perform a successfully complex segmentectomy. While VAL-MAP was initially designed to aid in tumor localization, the hybrid approach employing VAL-MAP and systemic indocyanine green injection showed efficacy in enabling segmentectomy. ${ }^{9}$ As a result, the 2 techniques complement one another, locating the nodule and identifying the intersegmental plane, 
allowing us to perform segmentectomies, even with a minimally invasive approach.

"John Keating: Why do I stand up here? [...] I stand upon my desk to remind myself that we must constantly look at things in a different way. [...] Just when you think you know something, you have to look at it in another way even though it may seem silly, or wrong. You must try!"

Dead Poets Society ${ }^{10}$

\section{References}

1. Yanagiya M, Amano Y, Hiyama N, Matsumoto J. Initial experience of virtualassisted lung mapping utilizing both indocyanine green and indigo carmine. Gen Thorac Cardiovasc Surg. 2021;69:1035-9.

2. Chen-Yoshikawa T, Tanaka S, Yamada Y, Yuataka Y, Nakajima D, Ohsumi A, et al. P2.17-26 Indocyanine green virtual assisted lung mapping (ICG-VALMAP): anyone can perform a successful preoperative marking for a small lung nodule. J Thorac Oncol. 2019;14:S894.
3. Chen-Yoshikawa T, Nakajima D, Hamaji M, Ohsumi A, Menju T, Sato T, et al. P2.16-27 Indocyanine green virtual assisted lung mapping (ICG-VAL-MAP): anyone can perform a visible preoperative marking successfully. J Thorac Oncol. 2018;13:S842.

4. Tokuno J, Chen-Yoshikawa TF, Nakajima D, Aoyama A, Motoyama H, Sato M, et al. Improved visualization of virtual-assisted lung mapping by indocyanine green. J Thorac Cardiovasc Surg Tech. 2021; 10:542-9.

5. Fang W. Commentary: is segmentectomy ready to be accepted as the standard of care? J Thorac Cardiovasc Surg. January 31, 2020 [Epub ahead of print].

6. Yanagiya M, Sato M. Palpitation and virtual-assisted lung mapping: not mutually exclusive but complementary to facilitate sublobar lung resection. J Thorac Dis. 2021;13:3927-9.

7. Goto T. Virtual-assisted lung mapping: is it actually better than finger palpation? J Thorac Dis. 2021;13:414-6.

8. Sato M, Kobayashi M, Kojima F, Tanaka F, Yanagiya M, Kosaka S, et al. Effect of virtual-assisted lung mapping in acquisition of surgical margins in sublobar lung resection. J Thorac Cardiovasc Surg. 2018;156:1691-701.e5.

9. Yanagiya M, Hiyama N, Matsumoto J. Hybrid technique of virtual-assisted lung mapping and systemic indocyanine green injection for extended segmentectomy. Surg Case Rep. 2020;6:273.

10. Schulman T. Dead Poets Society; 1989. Available at: https://www.youtube.com/ watch? $\mathrm{v}=\mathrm{U} 91 \mathrm{~W} 12 \mathrm{YpkD} 8$. Accessed August 9, 2021. 